H ORIZONS

\section{INTERESTING TIMES}

The old Chinese proverb 'May you live in interesting times has surely never been more apt than in the current HIV/AIDS arena in South Africa. Last month the Pharmaceutical Manufacturers Association, on behalf of 39 drug companies, unconditionally withdrew its challenge to legislation - passed in 1997 but not yet implemented - that allows the government to make or buy cheaper drugs. The drug companies, which include giants Merck, Bristol-Myers Squibb, GlaxoSmithKline and Boehringer Ingelheim, had claimed that a section of the 1997 law that allows South Africa to import or make cheaper drugs overrode their patent rights. The patents are necessary, they said, to encourage drug research. The Health Minister, Manto TshabalalaMsimang, is however quoted as saying that the victory allowed South Africa to pursue policies that she believes are critical to securing medicines at affordable rates and exercising 'wise control' over them.

South Africa must still reconcile the 1997 law with its commitment to honour international trade agreements and patent rules. The Health Minister said that the government has invited members of the pharmaceutical industry and the public to help draft the regulations governing the law. Mirryena Deeb, Chief Executive of the Pharmaceutical Manufacturers Association, termed it 'a partnership, a settlement based on trust'.

Mark Heywood of Treatment Action Campaign believes that the court case will embolden people in developing countries around the world to stand up for medicines that are affordable. GlaxoSmithKline's South African head, John Kearney, has said that the ball is now in South Africa's court to deliver AIDS drugs to its people. This is an awesome challenge, and not a moment too late. With 4.7 million South Africans (approximately $10 \%$ of the population) living with HIV infection, development of an infrastructure that will allow those afflicted access to life-saving drugs is a matter of extreme urgency. Even when the drugs are affordable we will need to sort out the operational issues that will enable them to be delivered to people in need. This will require concerted efforts from government as well as non-government and private structures to work together to really tackle our country's AIDS crisis.
Jean-Pierre Garnier, GlaxoSmithKline Chief Executive, summed things up well in a statement following the court case, saying 'this settlement meets the objectives of both the South African government and the pharmaceutical industry, but it is my fervent hope that the real winners will be patients'. We couldn't agree more.

As pressure for drug access shifts slightly from those who manufacture and price the drugs to those who deliver, such as government and medical aids, the country's wealthiest medical aid scheme, Discovery, came under some flack recently. It would appear that the brochures and information used to lure clients to join offer anti-HIV drugs in a misleading way. People have discovered to their horror after joining that the promised 'antiretroviral cover' amounts to little more than supportive counselling.

While Discovery is aggressively marketing itself to young professionals, and emphasising and rewarding healthy lifestyle, it has not taken into consideration that young people are the group most at risk of HIV/AIDS, and appears to have chosen not to reimburse for treatment for this disease.

Other medical aids in this country, such as Medscheme, which have had an antiretroviral treatment policy for at least 2 years, already have compelling data to show that the intervention is cost-constraining and will be even more so as drug prices continue to fall.

In a recent press article Discovery Health's general manager claimed that the misleading brochure was currently under revision and that independent brokers misinforming the public would be dealt with. We hope so.

There is no doubt that all the changes in the HIV/AIDS arena in recent months have made for interesting and exciting times. The onus is now very much on us to grasp the opportunities, to bring ourselves up to speed on treatment issues, and as quickly, safely and effectively as possible to translate this into benefits to our HIVinfected population.

\section{LINDA-GAIL BEKKER}

Managing Editor 